\title{
Adolescents' Empowerment for Mental Health Literacy in School: A Pilot Study on ProLiSMental Psychoeducational Intervention
}

\author{
Tânia Morgado 1,2,3,*iD, Luís Loureiro ${ }^{2,4}$, Maria Antónia Rebelo Botelho 5 , Maria Isabel Marques ${ }^{2,4}$, \\ José Ramón Martínez-Riera $^{6}{ }^{(D)}$ and Pedro Melo ${ }^{7}$ (D)
}

\section{check for}

updates

Citation: Morgado, T.; Loureiro, L.; Rebelo Botelho, M.A.; Marques, M.I.; Martínez-Riera, J.R.; Melo, P.

Adolescents' Empowerment for

Mental Health Literacy in School: A Pilot Study on ProLiSMental

Psychoeducational Intervention. Int.

J. Environ. Res. Public Health 2021, 18, 8022. https://doi.org/10.3390/ ijerph18158022

Academic Editor: Paul B. Tchounwou

Received: 4 June 2021

Accepted: 25 July 2021

Published: 29 July 2021

Publisher's Note: MDPI stays neutral with regard to jurisdictional claims in published maps and institutional affiliations.

Copyright: (c) 2021 by the authors. Licensee MDPI, Basel, Switzerland This article is an open access article distributed under the terms and conditions of the Creative Commons Attribution (CC BY) license (https:// creativecommons.org/licenses/by/ $4.0 /)$
1 Centro Hospitalar e Universitário de Coimbra-Hospital Pediátrico, Av. Afonso Romão, 3000-062 Coimbra, Portugal

2 Health Sciences Research Unit: Nursing, Escola Superior de Enfermagem de Coimbra, Av. Bissaya Barreto, 3004-011 Coimbra, Portugal; luisloureiro@esenfc.pt (L.L.); imarques@esenfc.pt (M.I.M.)

3 NursID: Innovation \& Development in Nursing, Center for Health Technology and Services Research, 4200-450 Porto, Portugal

4 Escola Superior de Enfermagem de Coimbra, Av. Bissaya Barreto, 3004-011 Coimbra, Portugal

5 Escola Superior de Enfermagem de Lisboa, Av. Dom João II, Lote 4.69.01, 1990-096 Lisboa, Portugal; rbotelho@esel.pt

6 Departamento Enfermeria Comunitaria, Medicina Preventiva y Salud Publica e Historia de la Ciencia Universidad de Alicante, E-03080 Alicante, Spain; jr.martinez@ua.es

7 Centre for Interdisiplinary Research in Health, Universidade Católica Portuguesa, 4169-005 Porto, Portugal; pmelo@porto.ucp.pt

* Correspondence: tmorgado@gmail.com
Abstract: Adolescence is a critical life phase for mental health and anxiety an emerging challenge for adolescents. Psychoeducational interventions to promote mental health literacy (MHL) on anxiety in adolescents are needed. This study aimed to test the primary outcome of a future full-scale trial: improvement of adolescents' anxiety MHL components on recognition, prevention strategies, and self-help strategies. A sample of 38 adolescents, 24 (63.2\%) females and 14 (36.8\%) males, with an average age of 14.50 years $(S D=0.89)$ participated in this study. Each class was allocated to the intervention group ( $\mathrm{IG}, n=21$ ) or the waiting list control group (WLCG, $n=17$ ) with single-blinded randomization. MHL was assessed using the QuALiSMental. The ProLiSMental psychoeducational intervention consists of four or eight weekly sessions of 90 or 45 min for adolescents, using different active pedagogical methods and techniques. There also are initial and final sessions with adolescents, legal guardians, and teachers. There was a significant improvement with a small to relatively strong effect size in many dimensions of anxiety MHL components. This study suggests the progression to the full-scale trial and values the important role of mental health and psychiatric nurses in the adolescents' empowerment for MHL in schools.

Keywords: adolescent; health literacy; health education; mental health; anxiety; mental health nursing; school nursing; pilot study

\section{Introduction}

The COVID 19 pandemic had implications for many dimensions of population health, including the mental health of people throughout the life cycle. In adolescents, several articles report the effects of the pandemic on their mental health [1-6], with approximately $38 \%$ of children and adolescents experiencing anxiety in the studies found in the systematic review carried out by Octavius et al. (2020) [5]. Some qualitative [7] and quantitative studies carried out in Portugal also report this reality [8,9]. Orgilés et al. (2021) [9] refer that the prevalence of anxiety and depressive symptoms was higher than usual and in the Portuguese sample, a prevalence of $26.5 \%$ was found, slightly higher than the prevalence (11.5\%) informed by Gaspar de Matos, Barrett, Dadds, and Shortt (2003) [10]. 
The "WHO Special Initiative for Mental Health (2019-2023): Universal Health Coverage for Mental Health" intends to empower communities and individuals to attain the highest standard of health, which can only be achieved when their mental health and well-being are ensured [11]. Interventions to promote adolescents' mental health and mental health literacy (MHL) on anxiety and to prevent pathological anxiety are necessary.

In the same way, health literacy (HL) is a population strategy for health promotion and public health [12,13], MHL is a significant strategy for mental health promotion, empowering the community to take action for better mental health $[14,15]$ and promoting community mental health. The MHL concept was defined in the late 1990s as the "knowledge and beliefs about mental disorders which aid their recognition, management, and prevention" [16]. In the 2000s, components of the concept of literacy were defined. These components consist of: (a) knowledge of how to prevent mental disorders; (b) recognition of when a disorder is developing; (c) knowledge of help-seeking options and treatments available; (d) knowledge of effective self-help strategies for milder problems; (e) first aid skills to support others who are developing a mental disorder or are in a mental health crisis [14]. More recently, the concept has focused more on "understanding how to obtain and maintain positive mental health" [17]. Bjørnsen, Eilertsen, Ringdal, Espnes, and Moksnes (2017) referred that this conceptualization advances previous perceptions of MHL as merely knowledge of mental disorders and is in line with the WHO's definition of mental health (Organization, 2013) and proposed the term "positive mental health literacy" [18].

Adolescence represents a critical life phase for mental health [19,20], but it also can be considered a developmental transition phase [21] with great opportunities for improving health [18] in which adolescents are particularly receptive to educational interventions to promote MHL. Cairns and Rossetto (2019) reinforce that MHL supports children, adolescents, and young people to attain positive mental health and wellbeing, as well as facilitating timely access to appropriate help when mental health problems occur [22].

In Portugal, the Health Literacy Action Plan 2019-2021 [23], referring to HL as an opportunity to promote health throughout the life cycle taking into account specificities of each stage of development, reinforces the need for interventions that promote adolescents ${ }^{\prime}$ HL, namely, in the school context, where adolescents spend most of their time. The Portugal School Health Program 2015 [24] presents the promotion of HL as a general objective and anxiety as an area of intervention in adolescence.

Psychoeducation emerges as a useful educational strategy often associated with prevention and intervention in mental illness, but it is also emerging in the promotion of mental health and MHL, particularly in the school context [25-31]. However, some studies still reported limitations and suggestions for future research [26,28,30-33].

In Portugal, the Manual of Good Practices in Health Literacy: Training of Health Professionals [34] reinforces the importance of psychoeducation as a tool in health literacy promotion. According to Portuguese regulations, mental health and psychiatric nurses assist the person throughout the life cycle, family, groups, and community in optimizing mental health and develop psychoeducational interventions. They also mobilize the context and individual, family, or group dynamics of the community [35] and promote MHL as one of the quality standards of mental health and psychiatric nursing care [36].

The ProLiSMental psychoeducational intervention to promote adolescents' MHL on anxiety at a school context was developed [37-42]. The purpose of this article is to present the results of a quasi-cluster randomized controlled trial used to pilot the ProLiSMental psychoeducational intervention, focused on knowledge, skills, and behavioral intentions of the following MHL components: (a) anxiety recognition; (b) anxiety prevention strategies; (c) anxiety self-help strategies.

\section{Materials and Methods}

Medical Research Council Framework [43,44] was used for the development of the ProLiSMental psychoeducational intervention as a complex intervention, throughout development and feasibility stages. Several previous studies were performed in this area 
with different aims: to identify the evidence, with a systematic review [37]; to identify the theory, with a narrative review [38]; to model processes and results, with adolescents' and education/health professionals' focus groups [39] and experts' e-Delphi [40]; to test the design and the methodology and assess the acceptability and feasibility, with an exploratory study [41,42]. A pilot study was followed, a small-scale study to assess the primary outcome of a future full-scale study $[45,46]$. Some authors have referred to the pertinence of using cluster randomized trials to pilot and evaluate complex interventions [47,48]. In this study, a pilot quasi-cluster randomized controlled trial, with pretest, posttest, and one-month follow-up design was used. This study is registered in www.clinicaltrials.org (accessed on 28 July 2021) with ID number NCT03872817.

\subsection{Participants}

Adolescents in the 9th grade from a school in the Central Region of Portugal were eligible to participate in the pilot study of the ProLiSMental psychoeducational intervention. According to exception criteria, they were excluded from the study if being students with special educational needs $(N=1)$; students who participated in the feasibility study of this intervention $(N=11)$, and students and legal guardians who did not accept to participate and did not sign the informed consent $(N=1)$. The class directors recruited eligible participants.

We have followed the authors' suggestion [45] of using a 95\% confidence interval approach to estimate sample size. From the total number of 67 adolescents attending the 9th grade at that school in the central region of Portugal, using G*Power 3.1 [49], with a $95 \%$ confidence level and a sampling error of $5 \%$, the sample size recommended for this study was 58 adolescents. Only 54 adolescents and their legal guardians from two classes in this school met the inclusion criteria, corresponding to a confidence level of $90 \%$ and a sampling error of $5 \%$. After class randomization, 29 adolescents were included in the intervention group (IG), which received the ProLiSMental psychoeducational intervention first, and 25 adolescents in the waiting list control group (WLCG), which received the same intervention after it was completed in the IG. However, of these only 38 adolescents participated in all sessions of the ProLiSMental psychoeducational intervention and all phases of data collection, with 21 (55.3\%) adolescents in the IG and $17(44.7 \%)$ adolescents in the WLCG, which represents a $70.4 \%$ retention rate (Figure 1).

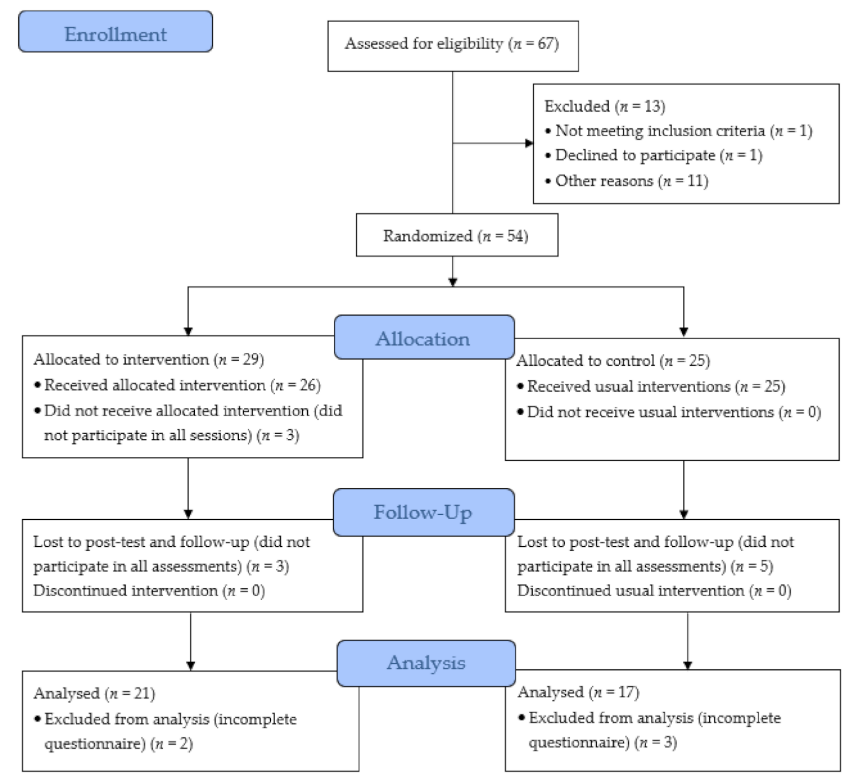

Figure 1. Participants' flow diagram through the phases of the quasi-cluster randomized controlled trial. 


\subsection{Intervention}

Based on the theoretical framework of several authors [13,14,16,21,50-54], the ProLiSMental psychoeducational intervention to promote adolescents' MHL on anxiety was developed. Its main objective was to enable adolescents in the school context to access, understand, evaluate, and apply information about mental health, to promote and maintain good mental health, and to facilitate anxiety recognition, prevention, and management.

The ProLiSMental psychoeducational intervention is structured in phases [42], whose total number of sessions can vary between 4 and 13 sessions and the total duration between $6 \mathrm{~h}$ and $13 \mathrm{~h}$ and $30 \mathrm{~min}$. The psychoeducational phase with adolescents consists of four weekly sessions of $90 \mathrm{~min}$ or eight weekly sessions of $45 \mathrm{~min}$. In each session, the following topics are approached: (1) "Recognise": mental health, emotions, and anxiety in adolescents"; (2) "Take care": mental health promotion and anxiety prevention, management, and self-help strategies; (3) "Seek help": mental health first aid actions, and seeking informal and formal help, including specialized health professionals; (4) "Action!": from knowledge on mental health and anxiety prevention, and management to action in everyday life.

In this pilot study, the ProLiSMental psychoeducational intervention was delivered in the school context by the principal researcher and three specialists nurses from primary health care (specializing in mental health and psychiatric nursing; child health and pediatric nursing or community health nursing) with experience in school health nursing and with previous 10-h training on the ProLiSMental psychoeducational intervention. In all sessions, three trainers, the researcher, and two of three primary health care nurses were always present, one of whom assumed the role of a non-participating observer.

\subsection{Outcomes Measures}

The QuALiSMental [55], the European Portuguese version of the "Survey of Mental Health Literacy in Young People-Interview Version" [20], was used in this quasi-cluster randomized controlled trial to measure adolescents' MHL. The first part of the questionnaire includes instructions for filling out and questions of sociodemographic characterization of adolescents (gender, age, with whom they live, educational background, and employment situation of legal guardians). The second part reports a situation of an adolescent's social anxiety [41], followed by questions regarding the different components of the MHL concept [14] from the perspective of knowledge, skills, and behavioral intentions [51]: (a) anxiety recognition; (b) anxiety prevention strategies; (c) anxiety self-help strategies; (d) help-seeking options; (e) anxiety mental health first aid. In this article, we will focus on the results for these first three components.

\subsection{Data Collection and Analysis}

Each class was allocated to the IG or the WLCG with single-blinded randomization by tossing a coin before the first assessment has been taken. The IG received the ProLiSMental psychoeducational intervention in April 2016, and three assessments were carried out with the collaboration of the teachers with the role of class directors, differentiating from the facilitators of the ProLiSMental psychoeducational intervention: (1) one day before (pretest); (2) one day after (posttest); (3) one month after (follow-up). After the ProLiSMental psychoeducational intervention was completed in the IG, the WLCG also received the same intervention in May 2016. In the WLCG, the three assessments took place: (1) one month before; (2) one day before; (3) one day after the intervention.

The statistical analysis was performed using the IBM-SPSS 27.0 software. After the inversion of three dimensions ("avoid stressful situations"; "drink alcohol to relax"; and "smoke to relax"), appropriate descriptive statistics (e.g., mean, standard deviation), and absolute and percentage frequencies were calculated, where appropriate. The Cochran $Q$ test with Dunn's post-hoc procedures, adjusted with Bonferroni's significance correction with a $p$-value of 0.05 was used. For the Cochran $Q$ test, the chance-corrected measure of effect size (R) was used, where $R$ is zero under chance conditions, unity when agreement among the $n$ subjects is perfect, and negative under conditions of disagreement [56]. In this 
study, we considered the effect size intervals: up to 0.2 -small; 0.2 to 0.5 -moderate; 0.6 to 0.8 - relatively large; 0.8 to 1 -large. To assess the association between the IG and the WLCG at each moment, the chi-square test $\left(\chi^{2}\right)$ was used.

\subsection{Ethical Procedures}

This study was approved by several organizations: (a) the Ethics Committee of the Regional Health Administration of Central Portugal (Administração Regional de Saúde do Centro), number 71/2015; (b) the National Data Protection Commission of Portugal (Comissão Nacional de Proteção de Dados), number 10880/2015; (c) General Direction of Education (Direção Geral da Educação), number 0506400001/2015; (d) Executive Board of the basic and secondary school where the study was carried out. Ethical principles of the revised Helsinki Declaration [57] (Association, 2013) were adopted and both adolescents and their legal guardians signed and delivered an informed consent form, which highlighted the voluntary participation and confidentiality ethical considerations.

\section{Results}

\subsection{Sociodemographic Characterization}

Of the 38 participants in this study, 24 (63.2\%) were female and $14(36.8 \%)$ were male, with an average age of 14.50 years $(S D=0.89)$. In the baseline, the results regarding the sociodemographic characteristics of the participants in the IG $(n=21)$ and the WLCG $(n=17)$ (Table 1) show the groups were homogeneous $(p>0.05)$.

Table 1. Participants' sociodemographic characteristics in the baseline $(N=38)$.

\begin{tabular}{|c|c|c|c|c|}
\hline \multicolumn{2}{|c|}{ Variable } & \multirow{2}{*}{$\begin{array}{c}\text { IG }(\boldsymbol{n = 2 1 )} \\
14.76(1.9)\end{array}$} & \multirow{2}{*}{$\begin{array}{c}\text { WLCG }(n=17) \\
14.18(0.39)\end{array}$} & \multirow{2}{*}{$\frac{p \text { (Effect Size }}{0.089(0.076)}$} \\
\hline Age in years, $M(S D)$ * & & & & \\
\hline Female, $n(\%)$ & & $13(61.9)$ & $11(64.7)$ & $0.859(0.029)^{b}$ \\
\hline Adolescents live with, $n(\%)$ & Parents & $21(100)$ & $17(100)$ & + \\
\hline \multirow{5}{*}{ Father's education, $n(\%)$} & 1st cycle of schooling & $1(4.8)$ & $1(5.9)$ & $0.755(0.219)^{\mathrm{c}}$ \\
\hline & 3rd cycle of schooling & $5(23.8)$ & $5(29.4)$ & \\
\hline & High school & $6(28.6)$ & $2(11.8)$ & \\
\hline & Bachelor's degree & $4(28.6)$ & $5(29.4)$ & \\
\hline & Master's/doctorate & $5(23.8)$ & $4(23.5)$ & \\
\hline \multirow{6}{*}{ Mother's education, $n(\%)$} & 1st cycle of schooling & $1(4.8)$ & $0(0)$ & $0.108(0.447)^{\mathrm{c}}$ \\
\hline & 2nd cycle of schooling & $0(0)$ & $1(5.9)$ & \\
\hline & 3rd cycle of schooling & $2(9.5)$ & $2(11.8)$ & \\
\hline & High school & $8(38.1)$ & $1(5.9)$ & \\
\hline & Bachelor's degree & $6(28.6)$ & $7(41.2)$ & \\
\hline & Master's/doctorate & $4(19.0)$ & $6(35.3)$ & \\
\hline $\begin{array}{l}\text { Father's professional } \\
\text { situation, } n(\%)\end{array}$ & Employeed & $20(95.2)$ & $16(94.1)$ & $0.543(0.149)^{\mathrm{c}}$ \\
\hline $\begin{array}{l}\text { Mother's professional } \\
\text { situation, } n(\%)\end{array}$ & Employeed & $21(100)$ & $17(100)$ & t \\
\hline
\end{tabular}

${ }^{*}$ Mean (M), Standard Deviation (SD); ${ }^{a}$ Mann Whitney $p$-value $\left(\eta^{2}\right) ;{ }^{b}$ Chi-square $p$-value $(\varphi) ;{ }^{c}$ L-R $p$-value $(V) ; ~ †$ Test not performed or measure not calculated.

\subsection{Anxiety Recognition}

Regarding the "anxiety recognition" component, Table 2 shows the findings in the three assessments. 
Table 2. Findings for "anxiety recognition" in the three assessments by group.

\begin{tabular}{|c|c|c|c|c|c|c|c|c|c|}
\hline \multirow{2}{*}{ Dimension } & & \multirow{2}{*}{$\begin{array}{c}\mathrm{a} \\
n(\%)\end{array}$} & \multirow{2}{*}{$\begin{array}{c}\mathrm{b} \\
n(\%)\end{array}$} & \multirow{2}{*}{$\begin{array}{c}\mathrm{c} \\
n(\%)\end{array}$} & \multirow{2}{*}{$Q^{\mathrm{e}}$} & \multirow{2}{*}{$R^{f}$} & \multicolumn{3}{|c|}{ Post-Hoc $\mathrm{g}$} \\
\hline & & & & & & & $a-b$ & a-c & b-c \\
\hline \multirow{2}{*}{ Anxiety } & IG & $5(23.8)$ & $19(90.5)^{d}$ & $18(85.7)$ & $26.143^{* * *}$ & 0.396 & $* * *$ & $* * *$ & ns \\
\hline & WLCG & $3(17.6)$ & $3(17.6)^{d}$ & $15(88.2)$ & $22.154^{* * *}$ & 0.434 & ns & $* * *$ & $* * *$ \\
\hline \multirow{2}{*}{ Social anxiety } & IG & $2(9.5)$ & $9(42.9)^{d}$ & $11(52.4)$ & $10.429 * *$ & 0.132 & $* *$ & ** & ns \\
\hline & WLCG & $0(0.0)$ & $0(0.0)^{d}$ & $6(35.3)$ & $12.000 * *$ & 0.233 & ns & $* *$ & $* *$ \\
\hline \multirow{2}{*}{ Fear of exposure } & IG & $10(47.6)$ & $6(28.6)$ & $5(23.8)$ & $3.500^{\mathrm{ns}}$ & 0.021 & $\ddagger$ & $\ddagger$ & $\ddagger$ \\
\hline & WLCG & $12(70.6)$ & $8(47.1)$ & $3(17.6)$ & $12.200 * *$ & 0.163 & ns & $* * *$ & ns \\
\hline \multirow{2}{*}{ Shyness } & IG & $16(76.2)^{d}$ & $3(14.3)$ & $4(19.0)$ & $19.625^{* * *}$ & 0.318 & $* * *$ & $* * *$ & ns \\
\hline & WLCG & $5(29.4)^{d}$ & $5(29.4)$ & $5(29.4)$ & $<0.001^{\mathrm{ns}}$ & -0.027 & $\ddagger$ & $\ddagger$ & $\ddagger$ \\
\hline \multirow{2}{*}{ Low self-esteem } & IG & $3(14.3)$ & $0(0.0)$ & $2(9.5)$ & $3.500^{\mathrm{ns}}$ & 0.021 & $\ddagger$ & $\ddagger$ & $\ddagger$ \\
\hline & WLCG & $4(23.5)$ & $2(11.8)$ & $0(0.0)$ & $4.800^{\mathrm{ns}}$ & 0.054 & $\ddagger$ & $\ddagger$ & $\ddagger$ \\
\hline \multirow{2}{*}{ Developmental problem } & IG & $3(14.3)$ & $0(0.0)$ & $1(4.8)$ & $3.500^{\mathrm{ns}}$ & 0.026 & $\ddagger$ & $\ddagger$ & $\ddagger$ \\
\hline & WLCG & $0(0.0)$ & $2(11.8)$ & $1(5.9)$ & $3.000^{\mathrm{ns}}$ & 0.014 & $\ddagger$ & $\ddagger$ & $\ddagger$ \\
\hline \multirow{2}{*}{ Depression } & IG & $0(0.0)$ & $0(0.0)$ & $0(0.0)$ & + & + & $\ddagger$ & $\ddagger$ & $\ddagger$ \\
\hline & WLCG & $0(0.0)$ & $2(11.8)$ & $1(5.9)$ & $2.000^{\mathrm{ns}}$ & $<0.001$ & $\ddagger$ & $\ddagger$ & $\ddagger$ \\
\hline
\end{tabular}

(a) First assessment; (b) second assessment; (c) third assessment; ${ }^{\mathrm{d}}$ significance associated with the Chi-Square test $\left(\chi^{2}\right)$ between group and dimension; ${ }^{e}$ comparison with Cochran's $Q$ test $(Q) ;{ }^{f}$ chance-corrected measures of effect size $(\mathrm{R}) ;{ }^{g}$ post-hoc procedures with Dunn's test, adjusted with Bonferroni's significance correction; ${ }^{* *} p<0.01 ;{ }^{* * *} p<0.001 ; \mathrm{ns}=$ not significant; $\dagger$ test not performed or measure not calculated; $\ddagger$ post-hoc procedure not calculated.

In the IG after the intervention, "anxiety" was significantly recognized, with moderate effect size, by the participants $(\mathrm{Q}=26.143 ; p<0.001 ; \mathrm{R}=0.396)$, with a significant association between the moments $\mathrm{a}-\mathrm{b}$ and $\mathrm{a}-\mathrm{c}(p<0.001)$. There were also statistically significant differences in the dimensions: "social anxiety" $(\mathrm{Q}=10.429 ; p<0.01 ; \mathrm{R}=0.132$, with a significant association between the moment a-b and a-c, $p<0.01)$ and "shyness" $(Q=19.625$; $p<0.001 ; \mathrm{R}=0.318$, with a significant association between the moment $\mathrm{a}-\mathrm{b}$ and $\mathrm{a}-\mathrm{c}$, $p<0.001$ ).

In the WLCG, the third assessment also shows significant differences, with moderate effect size, in the dimensions: "anxiety" $(\mathrm{Q}=22.154 ; p<0.001 ; \mathrm{R}=0.434$, with a significant association between the moment a-c and b-c, $p<0.001)$ and "social anxiety" $(\mathrm{Q}=12.000$; $p<0.01 ; R=0.233$, with a significant association between the moment $\mathrm{a}-\mathrm{c}$ and $\mathrm{b}-\mathrm{c}, p<0.01$ ).

In the analysis of independence between the groups at each moment, in this component there was a significant association between the IG and WLCG and the dimensions: "anxiety" $\left(\chi^{2}=20.442 ; p<0.001\right)$ and "social anxiety" $\left(\chi^{2}=10.986 ; p<0.001\right)$ in the second assessment.

Although about $47.6 \%$ and $70.6 \%$ of participants in the IG and WLCG groups respectively mentioned the "fear of exposure" in the baseline, in the second and the third assessment this percentage decreased statistically significant for the WLCG $(\mathrm{Q}=12.200$; $p<0.01 ; R=0.163$, with a significant association between the moments a-c, $p<0.001$ ).

\subsection{Anxiety Prevention Strategies}

In the "anxiety prevention strategies" component (Table 3), there were higher percentages of correct answers of the participants in the baseline for both groups, except for the dimensions "do not avoid stressful situations" and "have a religious or spiritual belief". In the first, there were no changes after the intervention for both groups. In the second, there was an improvement in the IG in the posttest and follow-up.

In the baseline, the highest percentages of correct answers were found in dimensions "regular contact with friends", "regular contact with family", and "improve self-esteem" for IG, which increased in the posttest. Particularly, to the dimension "regular contact with family", in the second assessment, there was a significant association to the WLCG $\left(\chi^{2}=5.828 ; p<0.05\right)$. 
Table 3. Findings for "anxiety prevention strategies" in the three assessments by group.

\begin{tabular}{|c|c|c|c|c|c|c|c|c|c|}
\hline \multirow{2}{*}{ Dimension } & & \multirow{2}{*}{$\begin{array}{c}\mathrm{a} \\
n(\%)\end{array}$} & \multirow{2}{*}{$\begin{array}{c}\mathrm{b} \\
n(\%)\end{array}$} & \multirow{2}{*}{$\begin{array}{c}\mathrm{c} \\
n(\%)\end{array}$} & \multirow{2}{*}{$Q^{\mathrm{e}}$} & \multirow{2}{*}{$R^{f}$} & \multicolumn{3}{|c|}{ Post-Hoc $\mathrm{g}$} \\
\hline & & & & & & & $\mathbf{a}-\mathbf{b}$ & a-c & b-c \\
\hline \multirow{2}{*}{ Exercise regularly } & IG & $16(76.2)$ & $20(95.2)$ & $20(95.2)$ & $8.000 * *$ & 0.062 & $*$ & * & ns \\
\hline & WLCG & $11(64.7)$ & $15(88.2)$ & $16(94.1)$ & $7.000 *$ & 0.082 & ns & * & ns \\
\hline \multirow{2}{*}{$\begin{array}{c}\text { Do not avoid stressful } \\
\text { situations }\end{array}$} & IG & $3(14.3)$ & $2(9.5)$ & $1(4.8)$ & $2.000^{\mathrm{ns}}$ & $<0.001$ & $\ddagger$ & $\ddagger$ & $\ddagger$ \\
\hline & WLCG & $2(11.8)$ & $2(11.8)$ & $1(5.9)$ & $1.000^{\mathrm{ns}}$ & -0.009 & $\ddagger$ & $\ddagger$ & $\ddagger$ \\
\hline \multirow{2}{*}{$\begin{array}{c}\text { Regular contact with } \\
\text { friends }\end{array}$} & IG & $19(90.5)$ & $20(95.2)$ & $19(90.5)$ & $1.000^{\mathrm{ns}}$ & -0.007 & $\ddagger$ & $\ddagger$ & $\ddagger$ \\
\hline & WLCG & 15 (88.2) & $13(76.5)$ & $15(88.2)$ & $4.000^{\mathrm{ns}}$ & 0.012 & $\ddagger$ & $\ddagger$ & $\ddagger$ \\
\hline \multirow{2}{*}{$\begin{array}{l}\text { Regular contact with } \\
\text { family }\end{array}$} & IG & $19(90.5)$ & $20(95.2)^{d}$ & $19(90.5)$ & $1.000^{\mathrm{ns}}$ & -0.007 & $\ddagger$ & $\ddagger$ & $\ddagger$ \\
\hline & WLCG & $12(70.6)$ & $11(64.7)^{d}$ & $13(76.5)$ & $1.500^{\mathrm{ns}}$ & -0.004 & $\ddagger$ & $\ddagger$ & $\ddagger$ \\
\hline \multirow{2}{*}{ Do not use drugs } & IG & $18(85.7)$ & $18(85.7)$ & $18(85.7)$ & $<0.001^{\mathrm{ns}}$ & -0.017 & $\ddagger$ & $\ddagger$ & $\ddagger$ \\
\hline & WLCG & $14(82.4)$ & $15(88.2)$ & $16(94.1)$ & $1.500^{\mathrm{ns}}$ & -0.008 & $\ddagger$ & $\ddagger$ & $\ddagger$ \\
\hline \multirow{2}{*}{ Regular sleep habits } & IG & $16(76.2)$ & $19(90.5)$ & $20(95.2)$ & $6.500 *$ & 0.042 & ns & * & ns \\
\hline & WLCG & $12(70.6)$ & $12(70.6)$ & $16(94.1)$ & $6.400 *$ & 0.051 & ns & ns & ns \\
\hline \multirow{2}{*}{ Do not drink alcohol } & IG & $16(76.2)$ & $18(85.7)$ & $17(81)$ & $0.857^{\mathrm{ns}}$ & -0.013 & $\ddagger$ & $\ddagger$ & $\ddagger$ \\
\hline & WLCG & $9(52.9)$ & $11(64.7)$ & $13(76.5)$ & $6.000 *$ & 0.027 & ns & $*$ & ns \\
\hline \multirow{2}{*}{ Healthy eating } & IG & $17(81.0)$ & $19(90.5)$ & $20(95.2)$ & $4,667^{\mathrm{ns}}$ & 0.021 & $\ddagger$ & $\ddagger$ & $\ddagger$ \\
\hline & WLCG & $12(70.6)$ & $13(76.5)$ & $17(100)$ & $7.000 *$ & 0.082 & ns & * & ns \\
\hline \multirow{2}{*}{ Regular relaxation training } & IG & $16(76.2)$ & $20(95.2)$ & $20(95.2)$ & $8.000 *$ & 0.063 & * & * & ns \\
\hline & WLCG & $13(76.5)$ & $13(76.5)$ & $14(82.4)$ & $0.286^{\mathrm{ns}}$ & -0.028 & $\ddagger$ & $\ddagger$ & $\ddagger$ \\
\hline \multirow{2}{*}{ Improve self-esteem } & IG & $19(90.5)$ & $20(95.2)$ & $20(95.2)$ & $2.000^{\mathrm{ns}}$ & $<0.001$ & $\ddagger$ & $\ddagger$ & $\ddagger$ \\
\hline & WLCG & $17(100)$ & $17(100)$ & $16(94.1)$ & $2.000^{\mathrm{ns}}$ & $<0.001$ & $\ddagger$ & $\ddagger$ & $\ddagger$ \\
\hline \multirow{2}{*}{$\begin{array}{l}\text { Have a religious or } \\
\text { spiritual belief }\end{array}$} & IG & $3(14.3)$ & $11(52.4)^{d}$ & $8(38.1)$ & $12.250 * *$ & 0.093 & $* *$ & ns & ns \\
\hline & WLCG & $2(11.8)$ & $3(17.6)^{d}$ & $4(23.5)$ & $1.500^{\mathrm{ns}}$ & -0.005 & $\ddagger$ & $\ddagger$ & $\ddagger$ \\
\hline
\end{tabular}

(a) First assessment; (b) second assessment; (c) third assessment; ${ }^{\mathrm{d}}$ significance associated with the Chi-Square test $\left(\chi^{2}\right)$ between group and dimension; ${ }^{\mathrm{e}}$ comparison with Cochran's $\mathrm{Q}$ test $(\mathrm{Q}){ }^{\mathrm{f}}{ }^{\mathrm{C}}$ chance-corrected measures of effect size (R); ${ }^{\mathrm{g}}$ post-hoc procedures with Dunn's test, adjusted with Bonferroni’s significance correction; ${ }^{*} p<0.05 ;{ }^{* *} p<0.01 ; \mathrm{ns}=$ not significant; $\ddagger$ post-hoc procedure not calculated.

In the IG, after the intervention, there were statistically significant differences in the dimensions: "exercise regularly" $(\mathrm{Q}=8.000 ; p<0.01 ; \mathrm{R}=0.062$, with a significant association between the moment $\mathrm{a}-\mathrm{b}$ and $\mathrm{a}-\mathrm{c}, p<0.05)$. There were also significant differences in "regular sleep habits" $(\mathrm{Q}=6.500 ; p<0.05 ; \mathrm{R}=0.042$, with a significant association between the moments a-c, $p<0.05)$; "regular relaxation training" $(\mathrm{Q}=8.000 ; p<0.05 ; \mathrm{R}=0.063$, with a significant association between the moments $\mathrm{a}-\mathrm{b}$ and $\mathrm{a}-\mathrm{c}, p<0.05)$. The dimension "have a religious or spiritual belief" $(\mathrm{Q}=12.250 ; p<0.01 ; \mathrm{R}=0.093$, had a significant association between the moments $a-b, p<0.01)$, reinforcing improvements after the intervention.

In the WLCG, after the intervention, differently from the IG, the dimensions "do not drink alcohol" ( $\mathrm{Q}=6.000 ; p<0.05 ; \mathrm{R}=0.027)$ and "healthy eating" $(\mathrm{Q}=7.000 ; p<0.05$; $\mathrm{R}=0.082)$ evidence a significant association between the moments a-c $(p<0.05)$.

\subsection{Anxiety Self-Help Strategies}

Regarding the "anxiety self-help strategies" component (Table 4), in the baseline, the highest percentages of correct answers of the participants were found in the dimensions "exercise regularly", "do not drink alcohol to relax", and "do not smoke to relax". These dimensions remained or increased in the posttest and follow-up for the IG and remained after the intervention for the WLCG, not showing statistically significant differences in the three moments of assessment. 
Table 4. Findings for "anxiety self-help strategies" in the three assessments by group.

\begin{tabular}{|c|c|c|c|c|c|c|c|c|c|}
\hline \multirow{2}{*}{ Dimension } & & \multirow{2}{*}{$\begin{array}{c}\mathrm{a} \\
n(\%)\end{array}$} & \multirow{2}{*}{$\begin{array}{c}\mathrm{b} \\
n(\%)\end{array}$} & \multirow{2}{*}{$\frac{\mathrm{c}}{n(\%)}$} & \multirow{2}{*}{$Q^{\mathrm{e}}$} & \multirow{2}{*}{$\mathbf{R}^{\mathrm{f}}$} & \multicolumn{3}{|c|}{ Post-Hoc $g$} \\
\hline & & & & & & & $\mathbf{a}-\mathbf{b}$ & a-c & b-c \\
\hline \multirow{2}{*}{ Exercise regularly } & IG & $19(90.5)$ & $20(95.2)$ & $19(90.5)$ & $1.000^{\mathrm{ns}}$ & -0.007 & $\ddagger$ & $\ddagger$ & $\ddagger$ \\
\hline & WLCG & $14(82.4)$ & $14(82.4)$ & $16(94.1)$ & $2.000^{\mathrm{ns}}$ & $<0.001$ & $\ddagger$ & $\ddagger$ & $\ddagger$ \\
\hline \multirow{2}{*}{ Regular relaxation training } & IG & $15(71.4)$ & $20(95.2)$ & $20(95.2)$ & $10.000^{* *}$ & 0.093 & * & * & ns \\
\hline & WLCG & $14(82.4)$ & $15(88.2)$ & $17(100.0)$ & $3.500^{\mathrm{ns}}$ & 0.027 & $\ddagger$ & $\ddagger$ & $\ddagger$ \\
\hline \multirow{2}{*}{ Meditation regularly } & IG & $12(57.1)$ & $20(95.2)^{d}$ & $20(95.2)$ & $16.000^{* * *}$ & 0.201 & ** & ** & ns \\
\hline & WLCG & $11(64.7)$ & $9(52.9)^{d}$ & $14(82.4)$ & $3.800^{\mathrm{ns}}$ & 0.032 & $\ddagger$ & $\ddagger$ & $\ddagger$ \\
\hline \multirow{2}{*}{ Acupuncture } & IG & $2(9.5)$ & $19(90.5)^{d}$ & $19(90.5)^{d}$ & $34.000^{* * *}$ & 0.614 & $* * *$ & $* * *$ & ns \\
\hline & WLCG & $3(17.6)$ & $2(11.8)^{d}$ & $10(58.8)^{d}$ & $14.250 * *$ & 0.187 & ns & ** & $* *$ \\
\hline \multirow{2}{*}{ Get up early and sunbathe } & IG & $14(66.7)$ & $21(100.0)^{d}$ & $21(100.0)^{d}$ & $14.000 * *$ & 0.222 & ** & ** & ns \\
\hline & WLCG & $6(35.3)$ & $10(58.8)^{d}$ & $13(76.5)^{d}$ & $6.727 *$ & 0.084 & ns & * & ns \\
\hline \multirow{2}{*}{$\begin{array}{l}\text { Therapy with a specialized } \\
\text { professional }\end{array}$} & IG & $14(66.7)$ & $17(81.0)^{\mathrm{d}}$ & $19(90.5)$ & $4.222^{\mathrm{ns}}$ & 0.032 & $\ddagger$ & $\ddagger$ & $\ddagger$ \\
\hline & WLCG & $7(41.2)$ & $8(47.1)^{d}$ & $14(82.4)$ & $9.556 * *$ & 0.110 & ns & * & * \\
\hline \multirow{2}{*}{$\begin{array}{l}\text { Website with credible } \\
\text { information }\end{array}$} & IG & $7(33.3)$ & $14(66.7)^{d}$ & $15(71.4)$ & $11.400 * *$ & 0.099 & * & ** & ns \\
\hline & WLCG & $4(23.5)$ & $4(23.5)^{d}$ & $10(58.8)$ & $8.000 *$ & 0.094 & ns & * & $*$ \\
\hline \multirow{2}{*}{ Self-help book } & IG & $7(33.3)$ & $15(71.4)^{d}$ & $14(66.7)$ & 8.769 * & 0.093 & * & ns & ns \\
\hline & WLCG & $8(47.1)$ & $6(35.3)^{d}$ & $9(52.9)$ & $1.167^{\mathrm{ns}}$ & -0.016 & $\ddagger$ & $\ddagger$ & $\ddagger$ \\
\hline \multirow{2}{*}{ Join a support group } & IG & $7(33.3)$ & $16(76.2)$ & $16(76.2)$ & $18.000^{* * *}$ & 0.157 & $* * *$ & $* * *$ & ns \\
\hline & CG & $8(47.1)$ & $8(47.1)$ & $12(70.6)$ & $6.400 *$ & 0.035 & ns & ns & ns \\
\hline \multirow{2}{*}{$\begin{array}{l}\text { Seek specialized mental } \\
\text { health help }\end{array}$} & IG & $9(42.9)$ & $18(85.7)^{\mathrm{d}}$ & $17(81.0)$ & $13.273^{* *}$ & 0.152 & $* *$ & $* *$ & ns \\
\hline & CG & $11(64.7)$ & $6(35.3)^{d}$ & $13(76.5)$ & $11.143^{* *}$ & 0.104 & ns & ns & $* *$ \\
\hline \multirow{2}{*}{$\begin{array}{l}\text { Do not drink alcohol to } \\
\text { relax }\end{array}$} & IG & $21(100.0)$ & $21(100.0)$ & $21(100.0)$ & + & + & $\ddagger$ & $\ddagger$ & $\ddagger$ \\
\hline & CG & $16(94.1)$ & $15(88.2)$ & $15(88.2)$ & $2.000^{\mathrm{ns}}$ & $<0.001$ & ns & ns & ns \\
\hline \multirow{2}{*}{ Do not smoke to relax } & IG & $19(90.5)$ & $21(100.0)$ & $21(100.0)$ & $4.000^{\mathrm{ns}}$ & 0.034 & ns & ns & ns \\
\hline & CG & $16(94.1)$ & $16(94.1)$ & 17 (100.0) & $1.000^{\mathrm{ns}}$ & -0.021 & ns & ns & ns \\
\hline
\end{tabular}

(a) First assessment; (b) second assessment; (c) third assessment; ${ }^{\mathrm{d}}$ significance associated with the Chi-Square test $\left(\chi^{2}\right)$ between group and dimension; ${ }^{\mathrm{e}}$ comparison with Cochran's $\mathrm{Q}$ test $(\mathrm{Q}) ;{ }^{\mathrm{f}}$ chance-corrected measures of effect size $(\mathrm{R}) ;{ }^{\mathrm{g}}$ post-hoc procedures with Dunn's test, adjusted with Bonferroni's significance correction; ${ }^{*} p<0.05 ;{ }^{* *} p<0.01 ;{ }^{* * *} p<0.001 ; \mathrm{ns}=$ not significant; $\dagger$ test not performed or measure not calculated; ‡ post-hoc procedure not calculated.

In the IG, this component was the one that showed statistically significant differences after the intervention in more dimensions. We found a significant association between the moment a-b and a-c. Found however small association in relatively large effect sizes, such as "regular relaxation training" $(\mathrm{Q}=10.000 ; p<0.01 ; \mathrm{R}=0.093)$; "meditation regularly" $(\mathrm{Q}=16.000 ; p<0.001 ; \mathrm{R}=0.201)$; "acupuncture" $(\mathrm{Q}=34.000 ; p<0.001 ; \mathrm{R}=0.614)$. Also in the dimensions "get up early and sunbathe" $(\mathrm{Q}=14.000 ; p<0.01 ; \mathrm{R}=0.222)$; "website with credible information" $(\mathrm{Q}=11.400 ; p<0.01 ; \mathrm{R}=0.099)$; "self-help book" $(\mathrm{Q}=8.769 ; p<0.05$; $\mathrm{R}=0.093)$; “join a support group" $(\mathrm{Q}=18.000 ; p<0.001 ; \mathrm{R}=0.157)$, and "seek specialized mental health help" $(\mathrm{Q}=13.273 ; p<0.01 ; \mathrm{R}=0.152)$.

In the analysis of independence between the groups at each moment, there was a significant association between the IG and WLCG in the second assessment. These differences were identified in the dimensions "meditation regularly" $\left(\chi^{2}=9.299 ; p<0.01\right)$; "acupuncture" $\left(\chi^{2}=23.543 ; p<0.001\right)$; "get up early and sunbathe" $\left(\chi^{2}=10.600 ; p<0.01\right)$; "therapy with a specialized professional" $\left(\chi^{2}=4.795 ; p<0.05\right)$; "website with credible information" ( $\left.\chi^{2}=7.012 ; p<0.01\right)$; "self-help book" $\left(\chi^{2}=4.962 ; p<0.05\right)$ and "seek specialized mental health help" $\left(\chi^{2}=10.264 ; p<0.001\right)$. These data showed improvements after the intervention. The significant association between the IG and WLCG continues in the third assessment in the dimensions: "acupuncture" $\left(\chi^{2}=5.208 ; p<0.05\right)$ and "get up early and sunbathe" $\left(\chi^{2}=5.522 ; p<0.05\right)$. This means that despite the increase of the 
correct answers in these dimensions in the WLCG, they were not enough to approach the values obtained in the IG after the intervention.

Additionally, in the WLCG after the intervention, differently from the IG, there were also significant improvements in the "therapy with a specialized professional" dimension $(\mathrm{Q}=9.556 ; p<0.01 ; \mathrm{R}=0.110)$, with a significant association between the moments a-c and b-c $(p<0.05)$.

\section{Discussion}

This pilot study of the ProLiSMental psychoeducational intervention assessed the primary outcome of the future full-scale trial: improvement of adolescents' knowledge, skills, and behavioral intentions in the following components of anxiety mental health literacy at a school context: (a) anxiety recognition; (b) anxiety prevention strategies; (c) anxiety self-help strategies.

Regarding the first component, there was a significant improvement with a moderate effect size in the recognition of anxiety as a normative emotion and the recognition of pathological anxiety, namely the signs and symptoms of social anxiety. These results are in line with other studies on the development of mental health literacy interventions [58-63]. There was also a reduction in the percentage of responses after intervention in the dimensions "shyness" and "fear of exposure", that despite its frequent association with social anxiety, recent evidence clarifies its similarities and differences [64-66].

It is positive that the adolescents present good results in the anxiety prevention strategies component in the baseline. However, after the intervention, there were significant improvements with small effect size, in the dimensions: "exercise regularly"; "regular sleep habits"; "regular relaxation training"; "have a religious or spiritual belief" in the IG, and "do not drink alcohol" and "healthy eating" in the WLCG. These results corroborate the importance of healthy lifestyles and coping strategies for promoting mental health and wellbeing and preventing pathological anxiety from the earliest age groups such as children and adolescents $[67,68]$. These results reinforce the need for interventions to promote mental health and MHL on these topics [18,27,29,69]. However, the results of the dimension "do not avoid stressful situations" as an emotion regulation strategy [70,71] decreased instead of increasing, throughout the three assessments, which suggest attention in the future fullscale trial. We wonder if this is due to any lack of clarification by facilitators or difficulty understanding by adolescents during the ProLiSMental psychoeducational intervention or when filling out the QuALiSMental questionnaire since this dimension appeared inverted.

In the "anxiety self-help strategies" component, some dimensions related to healthy lifestyles also showed high percentages in the baseline: "exercise regularly"; "do not drink alcohol to relax"; and "do not smoke to relax". Another dimension related to healthy lifestyles is "get up early and sunbathe", which showed statistically significant differences with moderate effect size in the IG after the intervention. There were other statistically significant improvements, with small to relatively large effect sizes, in many dimensions: "regular relaxation training"; "meditation regularly"; "acupuncture"; "website with credible information"; "self-help book"; "join a support group"; and "seek specialized mental health help" in the IG and "therapy with a specialized professional" in the WLCG. These results reinforce the importance of the positive view of the use of self-help strategies by young people, showing interest in learning new forms of self-help as a way of coping with anxiety $[14,58]$. Similar results regarding the "self-help strategies" component are reported in other studies with interventions to promote MHL in adolescents [58-63], despite the differences between them in terms of the content and methodology of the interventions, for example, the components of the MHL under study, the number of sessions, the facilitators and the recipients.

Given the current global context of the Covid 19 pandemic, an emerging suggestion of this study is the possibility of developing ProLiSMental psychoeducational intervention in a digital and online way as noted by a recent systematic review [72]. 
This intervention promotes adolescents' MHL as a protective factor of mental health in a universal way [50] and because we believe that simultaneously it contributes to the prevention of pathological anxiety, we suggest in future studies, in addition to MHL assessment, the possibility of assessing adolescents' anxiety levels before, after the intervention and over the time. We also suggest assessing satisfaction with the ProLiSMental psychoeducational intervention implementation, with validated instruments and even including legal guardians and teachers, since there are some sessions aimed at them. Reinforcing this idea, we also suggest future studies for the development of psychoeducational interventions to promote anxiety MHL aimed at these recipients.

Another interesting suggestion is the possibility of extending the ProLiSMental psychoeducational intervention to other contexts, from universal to a selective and indicated prevention perspective, reinforcing its potential to be developed throughout the mental health continuum [50].

Considering the advantages of cluster randomized trials $[47,48]$, we recognize the limitations related to the small sample size in this study, conditioning the retention and the randomization process, which increased the risk of bias.

For this reason, we suggest increasing the sample size in the full-scale trial, recruiting more participants, on the one hand, and increasing the number of facilitators, on the other hand, providing training on the ProLiSMental psychoeducational intervention, that will allow replication of the intervention on a larger scale.

The common areas of methodological uncertainty like recruitment, randomization, retention, blinding and data collection/outcome assessment methods [45,46] were tested by this pilot study. Considering its limitations and suggestions, the results of this pilot study allow us to proceed to a full-scale trial, without changes in the components of the complex ProLiSMental psychoeducational intervention.

\section{Conclusions}

This pilot quasi-cluster randomized controlled trial shows the improvement of adolescents' knowledge, skills, and behavioral intentions after the ProLiSMental psychoeducational intervention, in the components of anxiety MHL: (a) anxiety recognition; (b) anxiety prevention strategies; (c) anxiety self-help strategies. Overall, there was a significant improvement and small to relatively strong effect size in many dimensions of anxiety MHL components in the IG compared to the WLCG, considering the evolution throughout the three assessments. Was similar in the WLCG at the third assessment, after the ProLiSMental psychoeducational intervention.

We highlight the significant improvements after the intervention and follow-up. These improvements include the recognition of normal and pathological anxiety; the anxiety prevention strategies: "exercise regularly"; "regular sleep habits"; "regular relaxation training"; "have a religious or spiritual belief" in the IG. Also the self-help strategies as a way of coping with anxiety: "get up early and sunbathe"; "regular relaxation training"; "meditation regularly"; "acupuncture"; "website with credible information"; "self-help book"; "join a support group"; and "seek specialized mental health help" in the IG.

The ProLiSMental psychoeducational intervention showed improvements of knowledge, skills, and behavioral intentions in various components of anxiety MHL as predictors of behaviors that promote mental health and prevent pathological anxiety, reinforcing the progression to the full-scale trial.

Despite the development, the feasibility evaluation, and the pilot of ProLiSMental psychoeducational intervention began before the Covid 19 pandemic context, due to the increased levels of anxiety in the general population and adolescents, in particular, this intervention seems to be extremely useful.

We believe that mental health and psychiatric nurses according to their professional and legal framework, as members of transdisciplinary teams, can contribute in a solid and scientifically sustained way to the development and implementation of psychoeducational 
interventions to promote MHL, mental health, and anxiety prevention, and simultaneously, to empower adolescents in schools.

Mental health and psychiatric nurses have an important role in facilitating networking between different health care professionals and contexts, with important contributions in the identification and early intervention in mental health problems in children and adolescents.

Author Contributions: Conceptualization, T.M., L.L. and M.A.R.B.; methodology, T.M., L.L., and M.A.R.B.; validation, T.M., L.L., M.A.R.B., M.I.M., and P.M.; formal analysis, T.M., L.L., M.A.R.B., M.I.M., and P.M.; investigation, T.M., L.L., and M.A.R.B.; resources, T.M., L.L., M.A.R.B., M.I.M., and P.M.; data curation, T.M., L.L., and M.A.R.B.; writing-original draft preparation, T.M., L.L., and M.A.R.B.; writing-review and editing, T.M., L.L., M.A.R.B., M.I.M., P.M., and J.R.M.-R.; visualization, T.M., L.L., M.A.R.B., M.I.M., P.M., and J.R.M.-R.; supervision, T.M., L.L., M.A.R.B., M.I.M., P.M., and J.R.M.-R.; project administration, T.M. All authors have read and agreed to the published version of the manuscript.

Funding: This work is financially supported by National Funds through FCT-Fundação para a Ciência e a Tecnologia, I.P., under the project UIDB/04279/2020.

Institutional Review Board Statement: This study was approved by (a) the Ethics Committee of the Regional Health Administration of Central Portugal (Administração Regional de Saúde do Centro), number 71/2015; (b) the National Data Protection Commission of Portugal (Comissão Nacional de Proteção de Dados), number 10880/2015; (c) General Direction of Education (Direção Geral da Educação), number 0506400001/2015; (d) Executive Board of the basic and secondary school where the study was carried out. Ethical principles of the revised Helsinki Declaration [57] were adopted and both adolescents and their legal guardians signed and delivered an informed consent form, which highlighted the voluntary participation and confidentiality ethical considerations.

Informed Consent Statement: Informed consent was obtained from all subjects involved in the study.

Acknowledgments: The authors would like to thank Professor Anthony Jorm for always being available throughout the research process, the nurses who collaborated as facilitators, the collaborators of the school context where the study was developed, and the Health Sciences Research Unit: Nursing (UICISA:E), Escola Superior de Enfermagem de Coimbra, for always being available and providing support in all phases of the research process and development of the ProLiSMental psychoeducational intervention. We would also like to thank to the Centre for Interdisciplinary Research in Health, Universidade Católica Portuguesa (MAIEC project), for the contribution in the comprehensive vision of Community Health related to Mental Health and for the financing support of the project.

Clinical Trial Registration Information: ClinicalTrials.gov ID: NCT03872817.

Conflicts of Interest: The authors declare no conflict of interest.

\section{References}

1. de Figueiredo, C.S.; Sandre, P.C.; Portugal, L.C.L.; Mázala-De-Oliveira, T.; Chagas, L.D.S.; Raony, Í.; Ferreira, E.S.; Giestal-DeAraujo, E.; dos Santos, A.A.; Bomfim, P.O.-S. COVID-19 pandemic impact on children and adolescents' mental health: Biological, environmental, and social factors. Prog. Neuro-Psychopharmacol. Biol. Psychiatry 2021, 106, 110171. [CrossRef]

2. Fegert, J.M.; Vitiello, B.; Plener, P.L.; Clemens, V. Challenges and burden of the Coronavirus 2019 (COVID-19) pandemic for child and adolescent mental health: A narrative review to highlight clinical and research needs in the acute phase and the long return to normality. Child Adolesc. Psychiatry Ment. Health 2020, 14, 1-11. [CrossRef]

3. Guessoum, S.B.; Lachal, J.; Radjack, R.; Carretier, E.; Minassian, S.; Benoit, L.; Moro, M.R. Adolescent psychiatric disorders during the COVID-19 pandemic and lockdown. Psychiatry Res. 2020, 291, 113264. [CrossRef] [PubMed]

4. de Miranda, D.M.; Athanasio, B.D.S.; Oliveira, A.C.S.; Simoes-E-Silva, A.C. How is COVID-19 pandemic impacting mental health of children and adolescents? Int. J. Disaster Risk Reduct. 2020, 51, 101845. [CrossRef]

5. Octavius, G.S.; Silviani, F.R.; Lesmandjaja, A.; Angelina; Juliansen, A. Impact of COVID-19 on adolescents' mental health: A systematic review. Middle East Curr. Psychiatry 2020, 27, 1-8. [CrossRef]

6. Singh, S.; Roy, D.; Sinha, K.; Parveen, S.; Sharma, G.; Joshi, G. Impact of COVID-19 and lockdown on mental health of children and adolescents: A narrative review with recommendations. Psychiatry Res. 2020, 293, 113429. [CrossRef] [PubMed] 
7. Branquinho, C.; Kelly, C.; Arevalo, L.C.; Santos, A.; De Matos, M.G. "Hey, we also have something to say": A qualitative study of Portuguese adolescents' and young people's experiences under COVID-19. J. Community Psychol. 2020, 48, 2740-2752. [CrossRef]

8. Francisco, R.; Pedro, M.; DelVecchio, E.; Espada, J.P.; Morales, A.; Mazzeschi, C.; Orgilés, M. Psychological Symptoms and Behavioral Changes in Children and Adolescents During the Early Phase of COVID-19 Quarantine in Three European Countries. Front. Psychiatry 2020, 11, 570164. [CrossRef]

9. Orgilés, M.; Espada, J.P.; DelVecchio, E.; Francisco, R.; Mazzeschi, C.; Pedro, M.; Morales, A. Anxiety and Depressive Symptoms in Children and Adolescents during COVID-19 Pandemic: A Transcultural Approach. Psicothema 2021, 33, 125-130.

10. de Matos, M.G.; Barrett, P.; Dadds, M.; Shortt, A. Anxiety, depression, and peer relationships during adolescence: Results from the Portuguese national health behaviour in school-aged children survey. Eur. J. Psychol. Educ. 2003, 18, 3-14. [CrossRef]

11. World Health Organization. The WHO Special Initiative for Mental Health (2019-2023): Universal Health Coverage for Mental Health; WHO: Geneva, Switzerland, 2019; Available online: https:/ /apps.who.int/iris/handle/10665/310981 (accessed on 17 October 2019).

12. Nutbeam, D. Health literacy as a population strategy for health promotion. Jpn. J. Health Educ. Promot. 2017, 25, 210-222. [CrossRef]

13. Sørensen, K.; Broucke, S.V.D.; Fullam, J.; Doyle, G.; Pelikan, J.; Slonska, Z.; Brand, H.; (HLS-EU) Consortium Health Literacy Project European. Health literacy and public health: A systematic review and integration of definitions and models. BMC Public Health 2012, 12, 80. [CrossRef]

14. Jorm, A.F. Mental health literacy: Empowering the community to take action for better mental health. Am. Psychol. 2012, 67, 231-243. [CrossRef]

15. Jorm, A.F. Mental Health Literacy: Promoting Public Action to Reduce Mental Health Problems. In Mental Health Literacy: Empowering People and Communities to Act; Loureiro, L., Ed.; Unidade de Investigação em Ciências da Saúde Enfermagem (UICISA:E), Health Administration Press: Coimbra, Portugal, 2014; pp. 27-39. Available online: https://web.esenfc.pt/v02/pa/ conteudos /downloadArtigo.php?id_ficheiro=577\&codigo (accessed on 21 November 2014).

16. Jorm, A.F.; Korten, A.E.; Jacomb, P.A.; Christensen, H.; Rodgers, B.; Pollitt, P. "Mental health literacy": A survey of the public's ability to recognise mental disorders and their beliefs about the effectiveness of treatment. Med. J. Aust. 1997, 166, 182-186. [CrossRef]

17. Kutcher, S.; Wei, Y.; Coniglio, C. Mental Health Literacy. Can. J. Psychiatry 2016, 61, 154-158. [CrossRef]

18. Bjørnsen, H.N.; Eilertsen, M.B.; Ringdal, R.; Espnes, G.A.; Moksnes, U.K. Positive mental health literacy: Development and validation of a measure among Norwegian adolescents. BMC Public Health 2017, 17, 717. [CrossRef] [PubMed]

19. Jorm, A.F. The Concept of Mental Health Literacy. In International Handbook of Health Literacy: Research, Practice and Policy across the Life-Span; Okan, U.O.B., Levin-Zamir, D., Pinheiro, P., Sørensen, K., Eds.; Policy Press: Bristol, UK, 2019 ; pp. 53-66.

20. Jorm, A.F.; Wright, A.; Morgan, A.J. Beliefs about appropriate first aid for young people with mental disorders: Findings from an Australian national survey of youth and parents. Early Interv. Psychiatry 2007, 1, 61-70. [CrossRef] [PubMed]

21. Meleis, A.I. Transitions Theory Middle-Range and Situation-Specific Theories in Nursing Research and Practice; Springer: New York, NY, USA, 2010.

22. Cairns, K.; Rossetto, A. School-based mental health literacy interventions. In International Handbook of Health Literacy: Research, Practice and Policy across the Life-Span; Okan, U.O.B., Levin-Zamir, D., Pinheiro, P., Sørensen, K., Eds.; Policy Press: Bristol, UK, 2019; pp. 291-305.

23. da Saúde, D.-G. Plano de Ação Para a Literacia em Saúde 2019-2021; Direção-Geral da Saúde: Lisboa, Portugal, 2019.

24. da Saúde, D.-G. Programa Nacional de Saúde Escolar; Direção-Geral da Saúde: Lisboa, Portugal, 2015.

25. Brooks, H.; Irmansyah, I.; Lovell, K.; Savitri, I.; Utomo, B.; Prawira, B.; Iskandar, L.; Renwick, L.; Pedley, R.; Kusumayati, A.; et al. Improving mental health literacy among young people aged 11-15 years in Java, Indonesia: Co-development and feasibility testing of a culturally-appropriate, user-centred resource (IMPeTUs)—A study protocol. BMC Health Serv. Res. 2019, 19, 484. [CrossRef]

26. Das, J.K.; Salam, R.A.; Lassi, Z.S.; Khan, M.; Mahmood, W.; Patel, V.; Bhutta, Z.A. Interventions for Adolescent Mental Health: An Overview of Systematic Reviews. J. Adolesc. Health 2016, 59, S49-S60. [CrossRef] [PubMed]

27. Eschenbeck, H.; Lehner, L.; Hofmann, H.; Bauer, S.; Becker, K.; Diestelkamp, S.; Kaess, M.; Moessner, M.; Rummel-Kluge, C.; Saliz, H.; et al. School-based mental health promotion in children and adolescents with StresSOS using online or face-to-face interventions: Study protocol for a randomized controlled trial within the ProHEAD Consortium. Trials 2019, 20, 64. [CrossRef]

28. MacKenzie, K.; Williams, C. Universal, school-based interventions to promote mental and emotional well-being: What is being done in the UK and does it work? A systematic review. BMJ Open 2018, 8, e022560. [CrossRef] [PubMed]

29. O'Connor, C.A.; Dyson, J.; Cowdell, F.; Watson, R. Do universal school-based mental health promotion programmes improve the mental health and emotional wellbeing of young people? A literature review. J. Clin. Nurs. 2017, 27, e412-e426. [CrossRef] [PubMed]

30. Seedaket, S.; Turnbull, N.; Phajan, T.; Wanchai, A. Improving mental health literacy in adolescents: Systematic review of supporting intervention studies. Trop. Med. Int. Health 2020, 25, 1055-1064. [CrossRef] [PubMed]

31. Veltro, F.; Latte, G.; Ialenti, V.; Bonanni, E.; Di Padua, P.; Gigantesco, A. Effectiveness of psycho-educational intervention to promote mental health focused on emotional intelligence in middle-school. Ann. Ist Super Sanita 2020, 56, 66-71. [PubMed] 
32. Caldwell, D.M.; Davies, S.R.; Hetrick, S.E.; Palmer, J.C.; Caro, P.; López, J.; Gunnell, D.; Kidger, J.; Thomas, J.; French, C.; et al. School-based interventions to prevent anxiety and depression in children and young people: A systematic review and network meta-analysis. Lancet Psychiatry 2019, 6, 1011-1020. [CrossRef]

33. O'Reilly, M.; Svirydzenka, N.; Adams, S.; Dogra, N. Review of mental health promotion interventions in schools. Soc. Psychiatry Psychiatr. Epidemiol. 2018, 53, 647-662. [CrossRef]

34. da Saúde, D.-G. Manual de Boas Práticas Literacia em Saúde: Capacitação dos Profissionais de Saúde; Direção-Geral: Lisboa, Portugal, 2019.

35. República Portuguesa. Regulamento de Competências Específicas do Enfermeiro Especialista em Enfermagem de Saúde Mental e Psiquiátrica. Regulamento N 515. Diário da República, n. ${ }^{\circ}$ 122/2015, Série II de 2015-06-25.

36. República Portuguesa. Regulamento dos Padrões de Qualidade dos Cuidados Especializados em Enfermagem de Saúde Mental. Regulamento N 356. Diário da República n. ${ }^{\circ}$ 151/2018, Série II de 2018-08-07.

37. Morgado, T.; Botelho, M.R. Intervenções promotoras da literacia em saúde mental dos adolescentes: Uma revisão sistemática da literatura. Rev. Port. Enferm. Saúde Ment. 2014, 1, 90-96.

38. Morgado, T.M.; Loureiro, L.; Botelho, M. Psychoeducational interventions to promote adolescents' mental health literacy on anxiety in schools: Identifying theory for the development of a complex intervention. J. Child Adolesc. Psychiatr. Nurs. 2021. under review.

39. Morgado, T.M.; Loureiro, L.; Botelho, M. Psychoeducational intervention to promote mental health literacy among adolescents at school: A study with focus groups. Rev. Enferm. Refer. 2021, 5, e20133. [CrossRef]

40. Morgado, T.; Loureiro, L.; Botelho, M.R. Intervenção psicoeducacional ProLiSMental para adolescentes em contexto escolar: Validade de conteúdo através de e-Delphi modificado. Rev. Port. Enferm. Saúde Ment. 2020, 24, 43-50.

41. Morgado, T.; Loureiro, L.; Botelho, M.A.R. A utilização de vinhetas na saúde mental: Tradução e adaptação transcultural de uma vinheta de ansiedade social em adolescentes. Rev. Port. Investig. Comport. E Soc. 2020, 6, 1-11. [CrossRef]

42. Morgado, T.M.; Loureiro, L.; Botelho, M. Acceptability and feasibility of the ProLiSMental psychoeducational intervention to promote adolescents' mental health literacy on anxiety in a school context. Issues Ment. Health Nurs 2021. under review.

43. Craig, P.; Dieppe, P.; Macintyre, S.; Michie, S.; Nazareth, I.; Petticrew, M. Developing and evaluating complex interventions: The new Medical Research Council guidance. BMJ 2008, 337, a1655. [CrossRef]

44. Craig, P.; Petticrew, M. Developing and evaluating complex interventions: Reflections on the 2008 MRC guidance. Int. J. Nurs. Stud. 2013, 50, 585-587. [CrossRef]

45. Giangregorio, L.M.; Thabane, L. Pilot studies and feasibility studies for complex interventions: An introduction. In Complex Interventions in Health: An Overview of Research Methods, 1st ed.; Richards, D.A., Hallberg, I.R., Eds.; Routledge: Abingdon, UK, 2015; pp. 127-135.

46. Taylor, R.S.; Ukoumunne, O.C.; Warren, F.C. How to use feasibility and pilot trials to test alternative methodologies and methodological procedures prior to full-scale trials. In Complex Interventions in Health: An Overview of Research Methods, 1st ed.; Richards, D.A., Hallberg, I.R., Eds.; Routledge: Abingdon, UK, 2015; pp. 136-144.

47. Chan, C.L.; Leyrat, C.; Eldridge, S. Quality of reporting of pilot and feasibility cluster randomised trials: A systematic review. BMJ Open 2017, 7, e016970. [CrossRef]

48. Minary, L.; Trompette, J.; Kivits, J.; Cambon, L.; Tarquinio, C.; Alla, F. Which design to evaluate complex interventions? Toward a methodological framework through a systematic review. BMC Med. Res. Methodol. 2019, 19, 92. [CrossRef] [PubMed]

49. Faul, F.; Erdfelder, E.; Lang, A.-G.; Buchner, A. G*Power 3: A flexible statistical power analysis program for the social, behavioral, and biomedical sciences. Behav. Res. Methods 2007, 39, 175-191. [CrossRef]

50. Council, N.R.; Medicine, I.O. Preventing Mental, Emotional, and Behavioral Disorders among Young People: Progress and Possibilities; The National Academies Press: Washington, DC, USA, 2009.

51. Fishbein, M.; Ajzen, I. Predicting and Changing Behavior: The Reasoned Action Approach; Taylor \& Francis: New York, NY, USA, 2010.

52. Nutbeam, D. Health literacy as a public health goal: A challenge for contemporary health education and communication strategies into the 21st century. Health Promot. Int. 2000, 15, 259-267. [CrossRef]

53. Nutbeam, D. The evolving concept of health literacy. Soc. Sci. Med. 2008, 67, 2072-2078. [CrossRef]

54. Pender, N.J.; Murdaugh, C.L.; Parsons, M.A. Health Promotion in Nursing Practice; Prentice Hall: Hemel Hempstead, UK, 2002.

55. Loureiro, L. Questionário de Avaliação da Literacia em Saúde Mental—QuALiSMental: Estudo das propriedades psicométricas. Rev. Enferm. Ref. 2015, serIV, 79-88. [CrossRef]

56. Berry, K.J.; Johnston, J.E.; Mielke, P.W. An alternative measure of effect size for Cochran's Q test for related proportions. Percept. Mot. Skills 2007, 104, 1236-1242. [CrossRef]

57. Association, W.M. World Medical Association Declaration of Helsinki: Ethical principles for medical research involving human subjects. JAMA 2013, 310, 2191-2194. [CrossRef]

58. Campos, L.; Dias, P.; Duarte, A.; Veiga, E.; Dias, C.C.; Palha, F. Is It Possible to "Find Space for Mental Health" in Young People? Effectiveness of a School-Based Mental Health Literacy Promotion Program. Int. J. Environ. Res. Public Health 2018, 15, 1426. [CrossRef] [PubMed]

59. Chisholm, K.; Patterson, P.; Torgerson, C.; Turner, E.; Jenkinson, D.; Birchwood, M. Impact of contact on adolescents' mental health literacy and stigma: The SchoolSpace cluster randomised controlled trial. BMJ Open 2016, 6, e009435. [CrossRef] 
60. Coles, M.E.; Ravid, A.; Gibb, B.; George-Denn, D.; Bronstein, L.R.; McLeod, S. Adolescent Mental Health Literacy: Young People's Knowledge of Depression and Social Anxiety Disorder. J. Adolesc. Health 2016, 58, 57-62. [CrossRef] [PubMed]

61. Liddle, S.K.; Deane, F.P.; Batterham, M.; Vella, S.A. A Brief Sports-Based Mental Health Literacy Program for Male Adolescents: A Cluster-Randomized Controlled Trial. J. Appl. Sport Psychol. 2021, 33, 20-44. [CrossRef]

62. Perry, Y.; Petrie, K.; Buckley, H.; Cavanagh, L.; Clarke, D.; Winslade, M.; Hadzi-Pavlovic, D.; Manicavasagar, V.; Christensen, H. Effects of a classroom-based educational resource on adolescent mental health literacy: A cluster randomised controlled trial. J. Adolesc. 2014, 37, 1143-1151. [CrossRef]

63. Skre, I.; Friborg, O.; Breivik, C.; Johnsen, L.I.; Arnesen, Y.; Wang, C.E.A. A school intervention for mental health literacy in adolescents: Effects of a non-randomized cluster controlled trial. BMC Public Health 2013, 13, 873. [CrossRef] [PubMed]

64. Meyer, A.; Klein, D. Examining the relationships between error-related brain activity (the ERN) and anxiety disorders versus externalizing disorders in young children: Focusing on cognitive control, fear, and shyness. Compr. Psychiatry 2018, 87, 112-119. [CrossRef] [PubMed]

65. Robinson, O.J.; Pike, A.C.; Cornwell, B.; Grillon, C. The translational neural circuitry of anxiety. J. Neurol. Neurosurg. Psychiatry 2019, 90, 1353-1360. [CrossRef]

66. Tsui, T.Y.L.; Lahat, A.; Schmidt, L.A. Linking Temperamental Shyness and Social Anxiety in Childhood and Adolescence: Moderating Influences of Sex and Age. Child Psychiatry Hum. Dev. 2016, 48, 778-785. [CrossRef] [PubMed]

67. Ardic, A.; Erdogan, S. The effectiveness of the COPE healthy lifestyles TEEN program: A school-based intervention in middle school adolescents with 12-month follow-up. J. Adv. Nurs. 2017, 73, 1377-1389. [CrossRef] [PubMed]

68. Velten, J.; Bieda, A.; Scholten, S.; Wannemüller, A.; Margraf, J. Lifestyle choices and mental health: A longitudinal survey with German and Chinese students. BMC Public Health 2018, 18, 632. [CrossRef] [PubMed]

69. Johnstone, K.M.; Kemps, E.; Chen, J. A Meta-Analysis of Universal School-Based Prevention Programs for Anxiety and Depression in Children. Clin. Child Fam. Psychol. Rev. 2018, 21, 466-481. [CrossRef] [PubMed]

70. Golombek, K.; Lidle, L.; Tuschen-Caffier, B.; Schmitz, J.; Vierrath, V. The role of emotion regulation in socially anxious children and adolescents: A systematic review. Eur. Child Adolesc. Psychiatry 2020, 29, 1479-1501. [CrossRef]

71. Schäfer, J.Ö.; Naumann, E.; Holmes, E.A.; Tuschen-Caffier, B.; Samson, A. Emotion Regulation Strategies in Depressive and Anxiety Symptoms in Youth: A Meta-Analytic Review. J. Youth Adolesc. 2017, 46, 261-276. [CrossRef]

72. Patafio, B.; Miller, P.; Baldwin, R.; Taylor, N.; Hyder, S. A systematic mapping review of interventions to improve adolescent mental health literacy, attitudes and behaviours. Early Interv. Psychiatry 2021. [CrossRef] [PubMed] 